\title{
HUBUNGAN PENGETAHUN DENGAN KEPATUHAN PASIEN TUBERKULOSIS PARU DALAM PENGOBATAN DI PUSKESMAS PEMBANTU LIMAU SUNDAI BINJAI BARAT TAHUN 2016
}

\author{
Knowledge Relationship With the Compliance of Lung Tuberculosis Patients in \\ Treatment in The Sundai Limau Private Vocational School of Health \\ Center Binjai Barat 2016
}

\author{
Leny Suarni ${ }^{1}$ \\ ${ }^{1}$ Dosen Akademi Keperawatan Sehat Binjai \\ E-mail: lenysuarni2016@gmail.com
}

\begin{abstract}
Abstrak
Tuberkulosis paru merupakan penyakit menular yang umum dan banyak kasus bersifat mematikan. Hal terpenting yang harus diperhatikan dan dilakukan oleh penderita tuberkulosis paru yaitu keteraturan dalam minum obat, apabila hal ini tidak dilakukan maka pengobatan yang dilakukan sebelumnya menjadi sia-sia, dikarenakan kuman penyakit tuberkulosis paru menjadi kebal, sehingga sulit diobati. Penelitian ini menggunakan studi kolerasi bertujuan untuk mengetahui hubungan pengetahuan dengan kepatuhan pasien tuberkulosis paru dalam pengobatan di Puskesmas Pembantu Limau Sundai. Populasi adalah seluruh pasien di Puskesmas Pembantu limau Sundai, Sampel dari penelitian menggunakan total sampling yang berjumlah 20 orang. Pengumpulan data menggunakan kuesioner. Analisa data terdiri dari analisa univariat dan bivariat. Hasil penelitian menunjukkan bahwa tingkat pengetahuan dengan kategori baik sebanyak 12 orang $(60 \%)$, pengetahuan dengan kategori cukup dan kurang masing-masing sebanyak 4 orang (20\%). Mayoritas responden memiliki kepatuhan yang baik yaitu sebanyak 10 orang (50\%), kepatuhan dengan kategori cukup sebanyak 6 orang (30\%), dan kepatuhan dengan kategori kurang sebanyak 4 orang(20\%), serta ada hubungan pengetahuan dengan kepatuhan pasien tuberkulosis paru dalam pengobatan di Puskesmas Limau Sundai ( $\mathrm{t}$ hitung 2,502 > t tabel 0,456). Di harapkan kepada Puskesmas Limau Sundai lebih meningkatkan pemberian informasi melalui kegiatan penyuluhan kepada masyarakat khususnya pasien tuberkulosis Paru agar meningkatkan pengetahuan dan kepatuhan pasien dalam pengobatan tuberkulosis paru.
\end{abstract}

Kata Kunci : Pengetahuan, Kepatuhan, Tuberkulosis Paru

\begin{abstract}
Pulmonary tuberculosis is a common infectious disease and many cases are deadly. The most important thing that must be considered and carried out by patients with pulmonary tuberculosis is regularity in taking medicine, if this is not done then the treatment carried out previously becomes useless, because the pulmonary tuberculosis germs become immune, making it difficult to treat. This study uses a correlation study aimed to determine the relationship of knowledge with adherence to patients with pulmonary tuberculosis in treatment at the Sundai Limau Auxiliary Health Center. The population was all patients at the Sundai Maid Health Center, samples from the study used a total sampling of 20 people. Data collection using a questionnaire. Data analysis consisted of univariate and bivariate analysis. The results of the study showed that the level of knowledge in the good category was 12 people $(60 \%)$, knowledge with sufficient categories and less for 4 people $(20 \%)$. The majority of respondents had good adherence as many as 10 people (50\%), compliance with enough categories as many as 6 people (30\%), and compliance with less categories as many as 4 people $(20 \%)$, and there was a relationship of knowledge with compliance with pulmonary tuberculosis patients in treatment at Limau Sundai Health Center (t count 2.502>t table 0.456). It is hoped that the Limau Sundai Health Center will increase the provision of information through counseling activities to the community, especially patients with pulmonary tuberculosis in order to increase the knowledge and compliance of patients in the treatment of pulmonary tuberculosis.
\end{abstract}

Keywords: Knowledge, Compliance, Lung Tuberculosis 


\section{PENDAHULUAN}

Tuberculosis adalah penyakit yang disebabkan mycobakterium tuberculosis yang hampir seluruh organ tubuh dapat terserang olehnya, tapi yang paling banyak adalah penyakit infeksi yang disebabkan oleh mycobakterium tuberculosis dengan gejala yang sangat bervariasi (Mansjoer, 1999)

Insiden tuberkulosis paru menurut WHO memperkirakan bahwa jumlah seluruh kasus di dunia akan meningkat dari 7,5 juta jiwa pada tahun 1990 menjadi 10,2 juta pada tahun 2000. Jumlah kematian seluruhnya akan meningkat dari 2,5 juta menjadi 3,5 juta. Kenaikan tersebut sebagian di sebabkan oleh bertambahnya penduduk di negara-negara yang sedang berkembang. Namun di negara-negara miskin, tuberkulosis tetap merupakan masalah besar hampir sama seperti sediakala. Sesungguhnya, bila jumlah penduduk meningkat sedangkan angka tuberculosis akan berkurang sedikit, bukan berarti bahwa terdapat lebih banyak pasien tuberculosis di dunia saat ini di bandingkan dengan keadaan 20 tahun yang lalu (Crofton dan Norman 2002).

Di Sumatera Utara masih ada beberapa kabupaten atau kota yang masih dibawah target nasional untuk angka penemuan TB paru BTA (+) dari januari sampai desember 2013 seperti Tanah Karo (49,2\%), Nias Utara (51\%), Asahan $(53,9 \%)$, Nias Barat (12,9\%), Tobasa $(954,9 \%)$ dan juga ada yang tidak melaporkan selama 2 tahun seperti kota Gunung Sitoli. Sementara angka penemuan TB paru BTA (+) diatas angka nasional di antaranya Padang Lawas (144,9\%), Pakpak Barat (130,9\%) Tapanuli Tengah (130\%), dan Pematang Siantar (122,7\%). CDR atau yang sebelumnya disebut dengan Case Notification Rate (CNR) disumut, kata dia, presentasenya setiap tahun naik 5\%, dengan meningkatka jumlah fasilitas pelayanan kesehatan yang melaksanakan pengobatan TB dengan strategi DOTS (sumutprov).

Pemerintah melalui program nasional pengendalian TB telah melakukan berbagai upaya untuk menanggulangi TB, yakni dengan strategi DOTS (Directly observed Treatment Shortcourse). World
Health Organization (WHO)

merekomendasikan 5 komponen strategi DOTS yakni :Tanggung jawab politis dari para pengambil keputusan (termasuk dukungan dana). Diagnosis TB dengan pemeriksan dahak secara mikrisopis. Pengobatan dengan panduan obat anti Tuberculosis (OAT) jangka pendek dengan pengawasan langsung menelan obat (PMO). Kesinambungan persediaan OAT jangka pendek dengan mutu terjamin. Pencatatan dan pelaporan secara baku untuk memudahkan pemantauan dan evaluasi program penanggulangan TB (Depkes RI, 2005).

Meskipun berbagai upaya dilakukan oleh pemerintah, namun tanpa peran serta masyarakat tertentu tidak akan tercapai hasil yang optimal karena TB tidak hanya masalah kesehatan namun juga merupakan masalah sosial. Keberhasilan penanggulangan TB sangat bergantung pada tingkat kesadaran dan partisipasi masyarakat. Karena tuberkulosis merupakan suatu penyakit kronik yang salah satu kunci keberhasilannya adalah kepatuhan dari penderita (adherence). Kemungkinan ketidak patuhan penderita selama pengobatan TB sangatlah besar. Ketidak patuhan ini dapat terjadi karena beberapa hal, diantaranya adalah pemakaian obat dalam jangka panjang, jumlah obat yang diminum cukup banyak, serta kurangnya kesadaran penderita akan penyakitnya. Oleh karena itu perlu peran aktif dari tenaga kesehatan sehingga keberhasilan terapinya dapat dicapai (Depkes RI, 2005).

Berdasarkan survei yang dilakukan peneliti di Puskesmas Pembantu Limau Sundai ditemukan sebanyak 20 penderita TB paru, untuk itu perlu dilakukan penelitian tentang "Hubungan Pengetahuan Dengan Kepatuhan Pasien TB Paru di Puskesmas Pembantu Limau Sundai Binjai Tahun 2016".

\section{METODE}

Jenis penelitian yang digunakan bersifat korelasi yaitu metode penelitian yang dilakukan dengan tujuan mengungkapkan hubungan korelatif antar variabel, dan rancangan ini peneliti 
melibatkan minimal 2 variabel. (Hidayat, 2013 ). Penelitian ini bertujuan untuk mengetahui hubungan pengetahuan dengan kepatuhan pasien tuberkulosis paru dalam pengobatan di Puskesmas Pembantu Limau Sundai. Populasi dalam penelitian ini adalah seluruh pasien TB paru yang ada di Puskesmas Pembantu Limau Sundai sebanyak 20 orang. Teknik pengambilan sampel pada penelitian ini dilakukan dengan teknik total sampling yaitu teknik pengambilan sampel secara keseluruhan dari setiap anggota populasi sehinggga sampel berjumlah 20 orang. Pengumpulan data menggunakan kuesioner. Analisa data terdiri dari analisa univariat dan bivariat. Analisa univariat disajikan dengan membuat tabel distribusi frekuensi setiap variabel. Analisa bivariat dianalisis dengan menggunakan rumus hipotesis product moment correlation (Arikunto, 2013).

\section{HASIL PENELITIAN}

\section{Karakteristik Responden}

Responden penelitian ini didistribusikan berdasarkan umur, jenis kelamin, pekerjaan, dan pendidikan yang dapat dilihat pada tabel berikut ini:

\section{Tabel 1. Distribusi Responden Berdasarkan Kelompok Umur di Puskemas Pembantu Limau Sundai Binjai Barat Tahun 2016}

\begin{tabular}{cccc}
\hline No & Umur (tahun) & Frekuensi & Persentase \\
\hline 1 & $25-38$ & 7 & $35 \%$ \\
2 & $39-51$ & 9 & $45 \%$ \\
3 & $>60$ & 4 & $20 \%$ \\
\hline & Jumlah & $\mathbf{2 0}$ & $\mathbf{1 0 0 \%}$ \\
\hline
\end{tabular}

Tabel 1 menunjukkan bahwa Berdasarkan sebagian besar Responden berumur $39-51$ tahun sebanyak 9 orang
(45\%) dan sebagian kecilberumur $>60$ tahun sebanyak 4 orang $(20 \%)$.

Tabel 2. Distribusi Responden Berdasarkan Jenis Kelamin di Puskesmas Pembantu Limau Sundai Binjai Barat Tahun 2016

\begin{tabular}{cccc}
\hline No & Jenis Kelamin & Frekuensi & Persentase \\
\hline 1 & Laki- laki & 16 & $80 \%$ \\
2 & Perempuan & 4 & $20 \%$ \\
\hline & Jumlah & $\mathbf{2 0}$ & $\mathbf{1 0 0 \%}$ \\
\hline
\end{tabular}

sebanyak 16 orang $(80 \%)$ dan sebagian kecil Responden berjenis kelamin diketahui bahwa sebagian besar perempuan sebanyak 4 orang(20\%). respondenberjenis kelamin laki-laki

Tabel 3. Distribusi Responden Berdasarkan Pekerjaan di Puskesmas Pembantu Limau Sundai Binjai Barat Tahun 2016

\begin{tabular}{cccc}
\hline No & Pekerjaan & Frekuensi & Persentase \\
\hline 1 & IRT & 4 & $20 \%$ \\
2 & Petani & 8 & $40 \%$ \\
3 & Karyawan & 5 & $25 \%$ \\
4 & Wirausaha & 3 & $15 \%$ \\
\hline & Jumlah & $\mathbf{2 0}$ & $\mathbf{1 0 0 \%}$ \\
\hline
\end{tabular}


Berdasarkan tabel di atas dapat

sebanyak 8 orang $(40 \%)$, dan sebagian

diketahui bahwa sebagian besar

kecil responden bekerja sebagai

responden bekerja sebagai petani

wirausaha sebanyak 3 orang (15\%)

Tabel 4. Distribusi Responden Berdasarkan Tingkat Pendidikan di Puskesmas Pembantu Limau Sundai Binjai Barat Tahun 2016

\begin{tabular}{cccc}
\hline No & Pendidikan & Frekuensi & Persentase \\
\hline 1 & Tidak Sekolah & 4 & $20 \%$ \\
2 & SD & 6 & $30 \%$ \\
3 & SMP & 5 & $25 \%$ \\
4 & SMA & 5 & $25 \%$ \\
\hline & Jumlah & $\mathbf{2 0}$ & $\mathbf{1 0 0 \%}$ \\
\hline
\end{tabular}

Berdasarkan tabel di atas dapat

6 orang (30\%), dan sebagian kecil diketahui bahwa sebagian besar adalah SMP dan SMA.

responden berpendidikan SD sebanyak

Tabel 5. Distribusi Responden Berdasarkan Pengetahuan Pasien TB Paru dalam Pengobatan di Puskesmas Pembantu Limau Sundai Binjai Barat Tahun 2016

\begin{tabular}{cccc}
\hline No & Pengetahuan & Frekuensi & Persentase \\
\hline 1 & Baik & 12 & $60 \%$ \\
2 & Cukup & 4 & $20 \%$ \\
3 & Kurang & 4 & $20 \%$ \\
\hline & Jumlah & $\mathbf{2 0}$ & $\mathbf{1 0 0 \%}$ \\
\hline
\end{tabular}

Berdasarkan tabel di atas dapat diketahui bahwa sebagian besar pengetahuan responden tentang kepatuhan dalam proses pengobatan $\mathrm{TB}$ paru adalah kategori pengetahuan baik yaitu

sebanyak 12 orang (60\%), sedangkan yang paling kecil dengan pengetahuan dengan kategori cukup dan kurang yaitu masing-masing sebanyak 4 orang $(20 \%)$. 
PEMBAHASAN

\section{Pengetahuan Pasien TB paru tentang Pengobatan}

Berdasarkan tingkat pengetahuan pasien TB paru dalam pengobatan dengan baik dan teratur, maka penyakit tuberculosis paru dapat disembuhkan apabila pengobatan tersebut tidak dilakukan secara tidak teratur maka penyakit lebih sulit disembuhkan. Pengetahuan pasien TB paru dalam pengobatan, pengetahuan baik lebih banyak berjumlah 12 orang. Penyakit TB paru terbentuk suatu fokus infeksi primer merupakan tempat pembiakan dan penderita akan memberikan reaksi inflamasi (Djojodibroto, 2009).

\section{Kepatuhan pasien TB paru dalam pengobatan}

Berdasarkan tingkat kepatuhan pasien TB paru dalam pengobatan baik dan teratur maka penyakit TB paru dapat disembuhkan, penderita minum obat sesuai petunjuk yang telah ditentukan, kepatuhan pasien TB paru lebih banyak berjumlah 10 orang. Pasien harus minum obat sesuai waktuyang ditentukan (6-12 bulan) berturut tanpa terputus (Widjadja,2009).

\section{Hubungan pengetahuan dengan kepatuhan pasien TB paru dalam pengobatan.}

Hubungan pengetahuan dengan kepatuhan dalam pengobtan dapat dilihat dari uji kolerasi. Berdasarkan uji kolerasi diatas dapat diketahui nilai $\mathrm{t}$ hitung $=2,502$ dan $\mathrm{t}$ tabel $=0,456$, yang berarti bahwa $\mathrm{t}$ hitung 2,502 > t tabel 0,456 maka Ho ditolak dan Ha di terima. Hal ini berarti "ada Hubungan Pengetahuan dengan Kepatuhan pasien TB paru dalam Pengobatan". Jadi pasien harus mengikuti proses pengobatan dengan baik dan teratur pasien harus minum obat dalam jangka waktu (6-12 bulan) berturut tanpa terputus serta makan-makanan bergizi dan melibatkan petugas kesehatan dan keluarga.

\section{KESIMPULAN}

Berdasarkan hasil penelitian, maka dapat disimpulkan bahwa :
1. Berdasarkan umur mayoritas pasien beusia 39-51 tahun berjumlah 9 orang $(45 \%)$

2. Berdasarkan jenis kelamin mayoritas pasien laki-laki yaitu sebanyak 16 orang $(80 \%)$

3. Berdasarkan jenis pekerjaan mayoritas pasien memiliki pekerjaan sebagai petani sebanyak 8 orang (40\%).

4. Berdasarkan tingkat pendidikan yang paling banyak yaitu SD sebanyak 6 orang $(30 \%)$.

5. Pengetahuan pasien yang paling banyak yaitu pengetahuan yang baik sebanyak 12 orang $(60 \%)$

6. Kepatuhan pasien dalam pengobatan yang paling banyak yaitu kepatuhan yang baik sebanyak 10 orang (50\%)

7. Ada hubungan Pengetahuan dengan Kepatuhan pasien TB paru dalam Pengobatan TB Paru

\section{SARAN}

Adapun saran dalam penelitian ini adalah:

1. Diharapkan kepada tenaga kesehatan terkait untuk memberikan informasi kepada pasien TB paru tentang pentingnya kepatuhan dalam proses pengobatan TB paru.

2. Diharapkan kepada pasien TB paru di Puskesmas pembantu limau sundai binjai Barat untuk lebih meningkatkan pengetahuan dan kepatuhan pasien terhadap pengobatan TB paru.

\section{DAFTAR PUSTAKA}

Arikunto, S. 2013. Prosedur Penelitian : Suatu Pendekatan Praktek, Jakarta : Rineka Cipta.

Crofton, J, Dkk. 2002. Tuberkulosis Klinis, Clinical Tuberculosis, Jakarta : Widya Medika

Departemen Kesehatan RI, 2005, Pharmaceutical Care Untuk Penyakit Tuberkulosis, Direktorat Bina Farmasi Komunitas Dan Klinik Direktorat Jenderal Bina Kefarmasian Dan Alat Kesehatan, Jakarta 
Djojodibroto, D. 2009. Respirologi (Respiratory Medicine). Jakarta : EGC

Hidayat, A. Aziz Alimul, 2013. Metode Penelitian Keperawatan dan Teknik Analisis Data, Jakarta : Salemba Medika.

Mansjoer, A. 1999. Kapita Selekta Kedokteran Jakarta : Media Aesculapius 